OPEN ACCESS

Edited by:

Zhenhua Dai,

Guangdong Provincial Academy of

Chinese Medical Sciences, China

Reviewed by:

Jin Zheng,

Xi'an Jiaotong University Health

Science Center, China

Nianqiao Gong,

Huazhong University of Science and

Technology, China

*Correspondence:

Fu Xiong

xiongfu@smu.edu.cn

Yun Miao

miaoyunecho@126.com

tThese authors have contributed equally to this work

Specialty section:

This article was submitted to Alloimmunity and Transplantation,

a section of the journal

Frontiers in Immunology

Received: 21 September 2020

Accepted: 26 October 2020

Published: 19 November 2020

Citation:

Zhou Y, Wang Y, Ni H, Deng W, Liu D, Xu J, Cui N, Wu Y, Fu S, Xiao L, Liu H,

Qi K, Wang S, Xiong F and Miao $Y$

(2020) The Potential Significance of ABO Genotyping for Donor Selection

in Kidney Transplantation.

Front. Immunol. 11:608716.

doi: 10.3389/fimmu.2020.608716

\section{The Potential Significance of ABO Genotyping for Donor Selection in Kidney Transplantation}

Yi Zhou ${ }^{1 \dagger}$, Yuchen Wang ${ }^{1 \dagger}$, Haiqiang $\mathrm{Ni}^{1+}$, Wenfeng Deng ${ }^{1 \dagger}$, Ding $\mathrm{Liu}^{2}$, Jian $\mathrm{Xu}^{1}$, Naiqian Cui ${ }^{1}$, Yihan Wu ${ }^{1}$, Shaojie Fu ${ }^{1}$, Lulu Xiao ${ }^{1}$, Hailiang Liu ${ }^{3}$, Ka Qi ${ }^{4}$, Shaoqing Wang ${ }^{5}$, Fu Xiong ${ }^{3 *}$ and Yun Miao ${ }^{1 *}$

\footnotetext{
${ }^{1}$ Division of Transplantation, Nanfang Hospital, Southern Medical University, Guangzhou, China, ${ }^{2}$ Division of Transplantation, Zhujiang Hospital, Southern Medical University, Guangzhou, China, ${ }^{3}$ Department of Medical Genetics, School of Basic Medical Sciences, Southern Medical University, Guangzhou, China, ${ }^{4}$ Hemodialysis Center, Qinhuangdao Charity Hospital, Qinhuangdao, China, ${ }^{5}$ Nephrology Department, The First Affiliated Hospital of Chengdu Medical College, Chengdu, China
}

Background: The $\mathrm{ABO}$ blood group system is clinically important in kidney transplantation, but $\mathrm{ABO}$ genotyping fails to attract sufficient attention in some countries and regions. We identified one case of early graft dysfunction due to an $\mathrm{ABO}$ genotype mismatch. Here, we performed ABO genotyping in blood samples, analyzed grouping discrepancies, and investigated the weak A subgroup frequency in kidney transplantation candidates.

Methods: Blood samples from 302 uremic patients with grouping discrepancies and 356 uremic patients with type A blood were analyzed using standard serologic serotyping techniques. The ABO genotypes and alleles were analyzed by polymerase chain reaction sequence-specific primer (PCR-SSP) and sequence-based typing (PCR-SBT).

Results: All 302 uremic patients with grouping discrepancies carried weak ABO subgroup alleles and $77.48 \%$ carried irregular ABO antibodies. The discrepancy rate between serotyping and genotyping was $42.38 \%$, and the mismatching rate of donor selection according to serotype reached $88.74 \%$. And $2.53 \%$ of 356 uremic patients with type A blood were determined to be in the weak A subgroup, which was a higher percentage than that observed in the healthy Chinese population $(0.53 \%)$ by serological screening, but much lower than that observed in Caucasians (20\%).

Conclusion: We revealed the high risk of blood type misjudgment and genetically $\mathrm{ABO}$ mismatched transplantation if serological test was performed only in blood-group typing. Improved precision of $\mathrm{ABO}$ genotyping is crucial for successful kidney transplantation and reasonable organ allocation.

Keywords: ABO subtype, genotype, donor selection, serologic testing, kidney transplantation 


\section{INTRODUCTION}

The ABO blood group is the most clinically relevant blood group system in transplant medicine and it is genetically complicated with more than 200 alleles $(1,2)$. The $\mathrm{ABO}$ gene is located on the 34.1-34.2 area of human chromosome 9; the gene contains seven exons and six introns, and the coding region consists of 1065 bases (3). Variants in the ABO gene can lead to different blood group-specific glycosyltransferases, thus giving rise to subgroups within the blood system (4). Weak ABO subgroups refer to phenotypes with weak expression of $\mathrm{A}$ or $\mathrm{B}$ antigen compared to the common $\mathrm{ABO}$ alleles $\left(\mathrm{ABO}^{*} \mathrm{~A} 1.01, \mathrm{ABO}^{*} \mathrm{~A} 1.02, \mathrm{ABO}^{*} \mathrm{~B} 1.01\right.$, $\mathrm{ABO}^{*} \mathrm{O} 01.01$, and $\left.\mathrm{ABO}^{*} \mathrm{O} 01.02\right)(5)$.

$\mathrm{ABO}$ antigens are widely expressed on the membranes of red blood cells and tissue cells, as well as in saliva and body fluids (6, 7). There is a higher risk of graft loss in ABO-incompatible (ABOi) kidney transplantation $(8,9)$ since stimulated antibodies can bind directly to blood group antigens on the renal endothelial surface and cause acute rejection (AR). This may also cause subsequent platelet aggregation by activating complement response in conjunction with vascular endothelial cells, leading to chronic rejection (CR) and, ultimately, allograft failure (10).

An update to the Organ Procurement and Transplantation Network policy stipulates dual confirmation of the donor $\mathrm{A}$ or $\mathrm{AB}$ subtype. This policy permits A2-to-O and A2B-to-B transplantation in order to shorten the waiting time for group $\mathrm{O}$ and group B recipients, respectively (11-13). However, in many countries and regions, serological typing is the only criterion for $\mathrm{ABO}$ blood grouping for kidney transplantation $(14,15)$. We revealed one clinical case of unexplained and irreversible early graft dysfunction in a serologically matched pair, and it was verified by genotyping as A1-to- $\mathrm{A} 2$ transplantation.

In this study, we performed $\mathrm{ABO}$ gene detection of blood samples with grouping discrepancies retrospectively. We investigated the frequency of the weak A subgroup in type A candidates to explore the significance of $\mathrm{ABO}$ genotyping for precise donor selection in kidney transplantation.

\section{MATERIALS AND METHODS}

\section{Samples}

We retrospectively tested blood samples of a total of 302 kidney transplantation candidates who had never received a transplant reserved from Nanfang Hospital (Guangzhou, China), Qinhuangdao Charity Hospital (Qinhuangdao, China), and the First Affiliated Hospital of Chengdu Medical College (Chengdu, China) between January 2015 and December 2017. We also investigated 356 blood samples in the serological A group for subtype classification between January 2018 and October 2019 in Nanfang Hospital. Informed consent was obtained from patients, and the study was approved by the Ethics Committee of Nanfang Hospital (NFEC-2019-172), Southern Medical University.

\section{ABO Blood Group Testing}

$A B O$ serology of the samples was determined by monoclonal anti- $\mathrm{A}$, anti- $\mathrm{B}$, anti- $\mathrm{AB}$, and anti- $\mathrm{H}$; polyclonal anti- $\mathrm{A}$, anti- $\mathrm{B}$, and anti- $A B$ reagents (Brother Biotech, Changchun, China) according to the manufacturer's protocol; and an $\mathrm{ABO}$ red blood cell (RBC) kit for reverse typing. The intensity of microcolumn agglutination reaction $( \pm,+,++,+++,++++)$ was determined by trained staff according to the comparison card provided by the reagent manufacturer.

\section{DNA Preparation and Polymerase Chain Reaction Amplification}

Genomic DNA was extracted from $0.5 \mathrm{ml}$ EDTA-anticoagulated peripheral blood using a genomic DNA purification kit (Tianjin Super Biotechnology Developing Co., Ltd., Tianjin, China). The primers for polymerase chain reaction (PCR) were designed according to the published $\mathrm{ABO}$ gene sequence (GenBank Accession Number NC_000009.12), as listed in Supplementary

Table 1. The PCR reaction conditions were as follows: $96^{\circ} \mathrm{C}$ for $2 \mathrm{~min}$ (denaturation); $96^{\circ} \mathrm{C}$ for $20 \mathrm{~s}$ followed by $68^{\circ} \mathrm{C}$ for $60 \mathrm{~s}$ for 5 cycles; $96^{\circ} \mathrm{C}$ for $20 \mathrm{~s}, 65^{\circ} \mathrm{C}$ for $50 \mathrm{~s}$, and $72^{\circ} \mathrm{C}$ for $45 \mathrm{~s}$ for 10 cycles; $96^{\circ} \mathrm{C}$ for $20 \mathrm{~s}, 62^{\circ} \mathrm{C}$ for $50 \mathrm{~s}$, and $72^{\circ} \mathrm{C}$ for $45 \mathrm{~s}$ for 22 cycles; $72^{\circ} \mathrm{C}$ for $2 \mathrm{~min}$ (extension); and $4^{\circ} \mathrm{C}$ for thermal insulation. The PCR products were separated by $2.5 \%$ agarose gel electrophoresis at $150 \mathrm{~V}$ for 15 to $20 \mathrm{~min}$. Electrophoresis was continued until the control band separated completely from the positive band, and results were observed using an ultraviolet imaging system (GenoSens1860, Clinx, Shanghai, China).

\section{PCR Sequence-Specific Primer}

The polymerase chain reaction sequence-specific primer (PCRSSP) subtype blood genotyping kit (Tianjin Super Biotechnology Developing Co., Ltd., Tianjin) was used according to the manufacture's protocol. The mixture contained $110 \mu \mathrm{ldNTP}$ Buffer, $0.9 \mu \mathrm{l}$ TaqDNA polymerase (5 units/ $\mu$, Promega, USA), and $10 \mu \mathrm{l}$ sample DNA. The volume of amplification reaction system in each well was $10 \mu \mathrm{l}$ (11 wells per person).

\section{DNA Sequencing for Full the Coding Region of the ABO Gene}

The PCR amplification products were purified and then sequenced using Sanger's dideoxy termination method with a unidirectional specific primer which were the same as those of PCR (Supplementary Table 1). We analyzed the sequence data with BIO-Mutation ${ }^{\mathrm{TM}}$, and all obtained nucleotides sequences were compared with standard $\mathrm{ABO}$ polymorphism site sequences from the database red blood cells (dbRBC) of NCBI.

\section{Nomenclature of Mutations and ABO Alleles}

The $\mathrm{ABO}$ variants and alleles were named according to the nomenclature used by the International Society of Blood Transfusion (ISBT). If an ISBT allele name was not available, a name in the original literature was used in square brackets. 


\section{RESULTS}

\section{Clinical Characteristics of $\mathbf{3 0 2}$ Kidney Transplant Candidates}

Among 302 kidney transplant candidates, 192 (63.58\%) were male patients. A total of 101 (33.44\%) candidates had previously been pregnant; and 93 (30.79\%) had a prior blood transfusion. Twelve candidates had comorbid condition including hematologic diseases $(n=8,2.65 \%)$ and tumors $(n=4,1.32 \%)$.

\section{Genotype Distribution in 302 Transplant Candidates}

$\mathrm{ABO}$ serotyping with monoclonal reagents identified groups $\mathrm{O}$ $(n=19), A(n=43), B(n=63)$, and $A B(n=177)$ while the genotypes were groups $O(n=1), A(n=43), B(n=159)$, and $A B(n=99)$. The total discrepancy rate between serological and genetical typing reached $42.38 \%$ (128/302) (Table 1). ABO gene sequencing revealed that 302 candidates all carried weak ABO alleles, with 295 phenotypes belonging to weak ABO subgroups. A total of 41 genotypes were detected with the most frequent genotypes in genetically typed groups $\mathrm{A}, \mathrm{B}$, and $\mathrm{AB}$ were AelO1 (25.58\%, 11/ 43), B(A)O1 (23.90\%, 38/159), and A1Bw (22.22\%, 22/99), respectively (Figure 1). In total, 49 kinds of weak $\mathrm{ABO}$ alleles were analyzed. The most frequent alleles were $\mathrm{ABO}^{*} \mathrm{Aw} .37$ (gene frequency $22.22 \%, 18 / 81$ ), ABO ${ }^{\star}$ Bw.03 (gene frequency $19.82 \%$, $22 / 111$ ), $\mathrm{ABO}^{\star} \mathrm{BA} .02$ (gene frequency $59.77 \%, 52 / 87$ ), and $\mathrm{ABO}^{*}$ cisAB.01 (gene frequency $77.27 \%, 17 / 22$ ).

\section{The Detection of Irregular Antibody Intensity in $\mathbf{3 0 2}$ Transplant Candidates}

Among the samples, $77.48 \%(n=234)$ containing irregular $\mathrm{ABO}$ antibodies were identified by $\mathrm{ABO}$ blood group typing and reversed typing. In the serologically typed A group, $86.05 \%$ $(n=37)$ contained irregular anti-A antibodies; in the serologically typed B group, $68.25 \%(n=43)$ contained irregular anti-B antibodies; in the serologically typed $\mathrm{AB}$ group, $73.45 \%$ $(n=130)$ contained irregular anti-A antibodies and $23.73 \%$ $(\mathrm{n}=42)$ contained irregular anti-B antibodies. Interestingly, in the serologically typed $\mathrm{O}$ group, we found one sample showing negative anti-A antibodies, which was confirmed as O1O7. The detailed antibody intensity is listed in Table 2 .

\section{The Simulated Mismatching Rate in Donor Selection According to Serotype for 302 Transplant Candidates}

In this study, we analyzed donor selection according to serotype and genotype separately. Considering the $\mathrm{ABO}$ genotype and irregular blood antibodies, "ABO mismatch" was used to refer to a status in which a donor's blood type was selected by a serotyping mismatch with the actual $\mathrm{ABO}$ genotype of a recipient with intensive blood antibodies. The mismatching rate of donor selection according to serotype was $88.74 \%$ (268/ $302)$, and the rates in serological $\mathrm{O}, \mathrm{A}, \mathrm{B}$, and $\mathrm{AB}$ groups were $0 \%$ (0/19), 88.37\% (38/43), 91.30\% (59/63), and 96.61\% (171/177), respectively (Table 3 and Figure 2).

\section{Differences in Detection Rate of the Weak A Subgroup}

We collected the weak A subgroup distribution identified by serological screening in healthy Chinese populations from previous researches (16-19), and the frequency was estimated to be $0.35 \%$. Our data from 356 blood samples showed that $2.53 \%$ of blood type A kidney transplant candidates were identified as weak A subgroups by both serological and genetic test. Of these candidates, $1.97 \%$ (7/356) were A2 and 0.56\% (2/ 356) were Aw, which were significantly higher than that of healthy Chinese people in previous studies $\left(\chi^{2}\right.$ test, $\left.\mathrm{P}<0.01\right)$. But it's much lower than that of Caucasians $(20 \%)\left(\chi^{2}\right.$ test, $\mathrm{P}<0.01)$ due to genetic differences among ethnic groups $(20-22)$

(Tables 4 and 5).

\section{DISCUSSION}

We revealed the high risk of blood type misjudgment and genetically $\mathrm{ABO}$-mismatched transplantation based on both serological and genetic test. Improved precision of $\mathrm{ABO}$ genotyping is crucial for successful kidney transplantation and reasonable organ allocation.

Studies have reported the success of kidney transplantation across the blood group barrier $(23,24)$, but the risks for severe infection, antibody-mediated rejection, and postoperative bleeding were all increased in an ABO-incompatible patient groups. Britta

TABLE 1 | The discrepancy between serotype and genotype.

\begin{tabular}{|c|c|c|c|c|c|}
\hline Serotype & Individuals & Genotype & Phenotype & Individuals & Discrepancy rate (\%) \\
\hline \multirow[t]{3}{*}{$\mathrm{O}$} & 19 & AelO1, AelO2, AelO5 & $A$ & 7 & 94.74 \\
\hline & & BelO1, BelO2, BelO4 & $\mathrm{B}$ & 11 & \\
\hline & & 0107 & $\mathrm{O}$ & 1 & \\
\hline \multirow[t]{2}{*}{ A } & 43 & A1Bel, A2B ${ }^{*}, A w B$ & $A B$ & 14 & 32.56 \\
\hline & & A1A2, A2A2, A2O1, A2O2, A3O1, A3O2, AelO1, AelO2, AwO1, AwO2 & A & 29 & \\
\hline \multirow[t]{2}{*}{ B } & 63 & A1B3 & $A B$ & 2 & 3.17 \\
\hline & & BBw, B3O1, B3O2, BelO1, BelO2, BelO4, BwO1, BwO2, BwO6, BwO7 & $\mathrm{B}$ & 61 & \\
\hline \multirow[t]{3}{*}{$A B$} & 177 & A2O1, AelO1 & A & 7 & 53.11 \\
\hline & & $B 301, B(A) O 1, B(A) O 2, B(A) O 56, B(A) B$ & $\mathrm{~B}$ & 87 & \\
\hline & & $\begin{array}{l}\text { A1Bw, A1B3, A2B, A3B, AelB, AwB, AwBw, B(A)A1, } \\
\text { cisAB/O1, cisAB/O2, cisAB/A1, cisAB/B }\end{array}$ & $\mathrm{AB}$ & 83 & \\
\hline
\end{tabular}

${ }^{*} B$ stands for B.01, B.02, B.03 according to ISBT. 


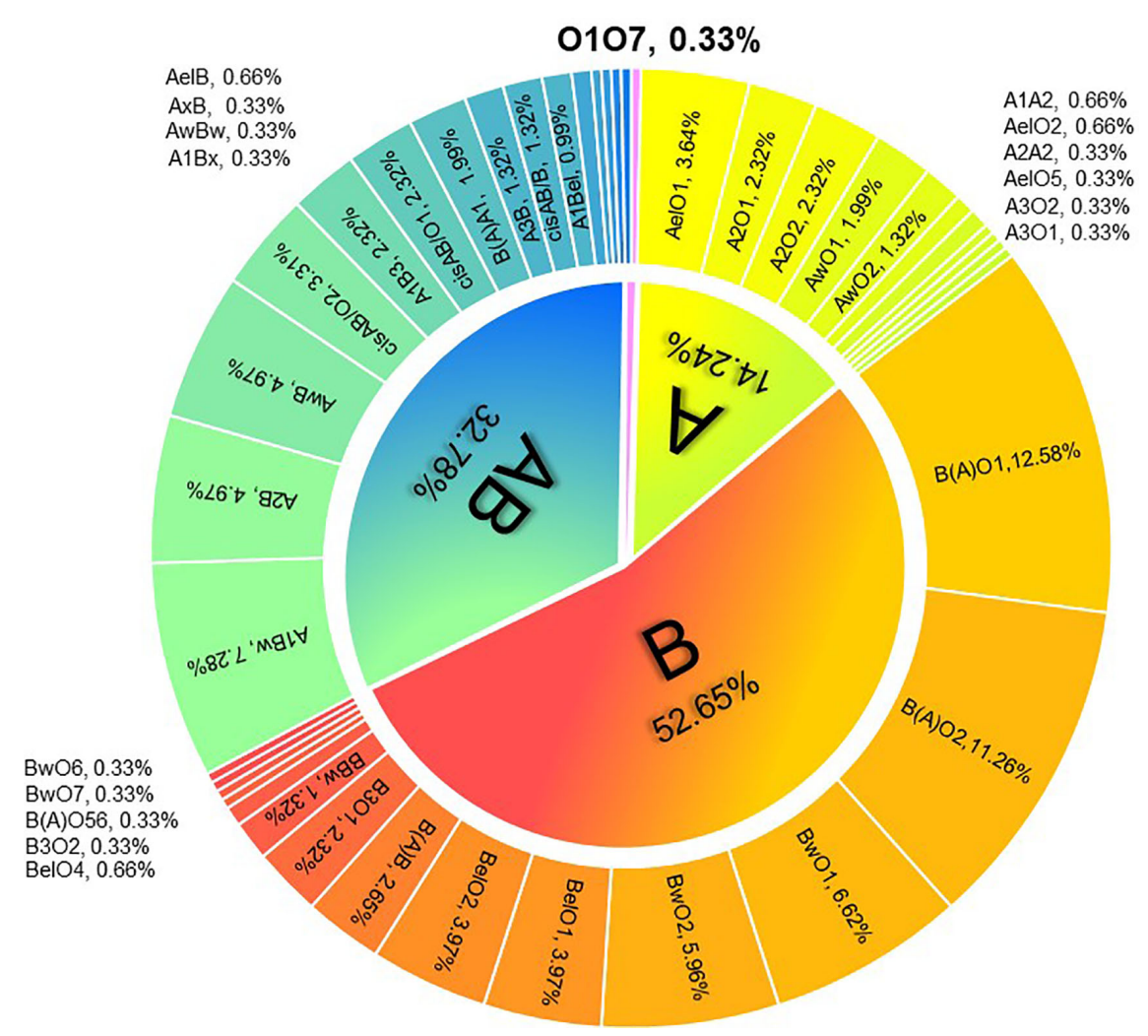

FIGURE 1 | Distribution of ABO genotypes in 302 kidney transplantation candidates with ABO grouping discrepancies.

TABLE 2 | The serological characteristics of 302 candidates.

\begin{tabular}{|c|c|c|c|c|c|c|c|c|c|c|c|c|}
\hline \multirow[t]{3}{*}{ Serotype } & \multicolumn{6}{|c|}{ Anti-A antibody $\%$} & \multicolumn{6}{|c|}{ Anti-B antibody \% } \\
\hline & \multirow{2}{*}{$\begin{array}{c}\text { Irregular } \\
\text { antibody (n) }\end{array}$} & \multicolumn{5}{|c|}{ Intensity (n) } & \multirow{2}{*}{$\begin{array}{c}\text { Irregular } \\
\text { antibody (n) }\end{array}$} & \multicolumn{5}{|c|}{ Intensity (n) } \\
\hline & & \pm & + & ++ & +++ & ++++ & & \pm & + & ++ & +++ & ++++ \\
\hline$O^{\star}(n=19)$ & $94.74(n=18)$ & $\begin{array}{l}26.32 \\
(n=5)\end{array}$ & $\begin{array}{l}10.53 \\
(n=2)\end{array}$ & $\begin{array}{r}47.37 \\
(n=9)\end{array}$ & $\begin{array}{l}5.26 \\
(n=1)\end{array}$ & $\begin{array}{l}5.26 \\
(n=1)\end{array}$ & $100(n=19)$ & $\begin{array}{l}52.63 \\
(n=10)\end{array}$ & $\begin{array}{l}5.26 \\
(n=1)\end{array}$ & $\begin{array}{l}42.11 \\
(n=8)\end{array}$ & 0 & 0 \\
\hline$A(n=43)$ & $86.05(n=37)$ & 0 & $\begin{array}{l}48.84 \\
(n=21)\end{array}$ & $\begin{array}{l}37.21 \\
(n=16)\end{array}$ & 0 & 0 & 100 & $\begin{array}{l}4.65 \\
(n=2)\end{array}$ & $\begin{array}{l}9.30 \\
(n=4)\end{array}$ & $\begin{array}{l}4.65 \\
(n=2)\end{array}$ & $\begin{array}{l}11.63 \\
(n=5)\end{array}$ & $\begin{array}{l}69.77 \\
(n=30)\end{array}$ \\
\hline$B(n=63)$ & 100 & 0 & 0 & 0 & $\begin{array}{l}28.57 \\
(n=18)\end{array}$ & $\begin{array}{l}71.43 \\
(n=45)\end{array}$ & $68.25(n=43)$ & $\begin{array}{l}52.38 \\
(n=33)\end{array}$ & $\begin{array}{l}15.87 \\
(n=10)\end{array}$ & 0 & 0 & 0 \\
\hline $\begin{array}{l}A^{*} \\
(n=177)\end{array}$ & $73.45(n=130)$ & $\begin{array}{l}3.39 \\
(\mathrm{n}=6)\end{array}$ & $\begin{array}{l}22.60 \\
(n=40)\end{array}$ & $\begin{array}{l}16.95 \\
(n=30)\end{array}$ & $\begin{array}{l}23.16 \\
(n=41)\end{array}$ & $\begin{array}{c}7.34 \\
(n=13)\end{array}$ & $23.73(n=42)$ & $\begin{array}{l}11.30 \\
(n=20)\end{array}$ & $\begin{array}{c}9.04 \\
(n=16)\end{array}$ & $\begin{array}{l}2.26 \\
(n=4)\end{array}$ & $\begin{array}{l}1.13 \\
(\mathrm{n}=2)\end{array}$ & 0 \\
\hline
\end{tabular}

${ }^{*}$ One sample in blood group $O$ does not contain anti-A antibody, and 5 samples in blood group $A B$ contain both anti-A antibody and anti-B antibody.

Eiz-Vesper et al. showed that different ABO genotypes hiding behind identical phenotypes encode for different sets of glycosyltransferases, which provide a source for minor histocompatibility antigens in allogeneic peripheral blood progenitor cell transplantation. Thus, considering allelic ABO sequences, at least $15 \%$ of all phenotypically $\mathrm{ABO}$-matched transplant pairs can be expected to have genotype constellations relevant to graft-versus-host disease (GVHD) (25). Ushigome et al. revealed a higher risk of transplant glomerulopathy caused by chronic or active antibody-mediated rejection within 1 year after ABOi kidney transplantation (26). Dashkova et al. examined the irregular anti-A1 antibody-containing serum from 43 samples with A2 and A2B blood groups, which might be the reason for posttransfusion reactions or complications in recipients (27). These findings indicated that ABO incompatibility and anti-A1/ $\mathrm{A} / \mathrm{B}$ titers may be the strongest risk factors for graft rejection after kidney transplantation.

In the present study, $\mathrm{ABO}$ gene sequencing revealed that all the 302 candidates carried weak ABO alleles, leading to grouping discrepancies observed in the reciprocal serotyping. Therefore, 
TABLE 3 | The discrepancy of donor selection according to serotype and genotype.

\begin{tabular}{|c|c|c|c|c|c|c|}
\hline Serotype & Genotype & Individuals & \multicolumn{2}{|c|}{ Donor selection } & Match/mismatch & Mismatch\% \\
\hline \multirow[t]{2}{*}{$\mathrm{O}$} & AelO1, AelO2, AelO5 & 7 & $\mathrm{O}$ & $\mathrm{O}$ & Match & \\
\hline & 0107 & 1 & 0 & 0 & Match & \\
\hline Sum & & 19 & & & & $0(0 / 19)$ \\
\hline \multirow[t]{3}{*}{$A$} & $\mathrm{~A} 1 \mathrm{~A} 2$ & 2 & $A$ & A & Match & \\
\hline & A1Bel & 3 & A & $\mathrm{O} / \mathrm{A}$ & Match & \\
\hline & $A 2 B^{\star}, A w B$ & 11 & $A$ & $\mathrm{O} / \mathrm{B}$ & Mismatch & \\
\hline Sum & & 43 & & & & $88.37(38 / 43)$ \\
\hline $\mathrm{B}$ & $\begin{array}{l}\mathrm{B} 3 \mathrm{O} 1, \mathrm{~B} 3 \mathrm{O} 2, \mathrm{BelO1}, \mathrm{BelO} 2, \\
\mathrm{BelO4}, \mathrm{BwO1}, \mathrm{BwO2}, \mathrm{BwO6} \text {, } \\
\text { BwO7 }\end{array}$ & 57 & B & $\mathrm{O}$ & Mismatch & \\
\hline \multirow{10}{*}{$A B$} & $\mathrm{~B} 3 \mathrm{O} 1$ & 6 & $A B$ & $\mathrm{O}$ & Mismatch & \\
\hline & $\mathrm{B}(\mathrm{A}) \mathrm{O} 1, \mathrm{~B}(\mathrm{~A}) \mathrm{O} 2, \mathrm{~B}(\mathrm{~A}) \mathrm{O} 56$ & 73 & $A B$ & $\mathrm{O} / \mathrm{B}$ & Mismatch & \\
\hline & $B(A) B$ & 8 & $A B$ & $\mathrm{~B} / \mathrm{O}$ & Mismatch & \\
\hline & AwBw & 1 & $A B$ & 0 & Mismatch & \\
\hline & A1Bw, A1B3 & 28 & $A B$ & $\mathrm{O} / \mathrm{A}$ & Mismatch & \\
\hline & A2B,A3B, AelB, AwB & 26 & $A B$ & $\mathrm{O} / \mathrm{B}$ & Mismatch & \\
\hline & $\mathrm{B}(\mathrm{A}) \mathrm{A} 1$ & 6 & $A B$ & $\mathrm{AB} / \mathrm{O} / \mathrm{A} / \mathrm{B}$ & Match & \\
\hline & cisAB/O1, cisAB/O2 & 17 & $A B$ & O & Mismatch & \\
\hline & cisAB/A1 & 1 & $A B$ & $\mathrm{~A} / \mathrm{O}$ & Mismatch & \\
\hline & cisAB/B & 4 & $A B$ & $\mathrm{~B} / \mathrm{O}$ & Mismatch & \\
\hline Sum & & 177 & & & & $96.61(171 / 177$ \\
\hline
\end{tabular}

${ }^{*} B$ stands for B.01, B.02, B.03 according to ISBT.

the only serological test bears a serious risk for erroneous typing of $\mathrm{ABO}$ group, especially for blood groups $\mathrm{O}$ and $\mathrm{AB}$ based on the results of our cohort. Accordingly, our findings indicated that misjudgment also existed in donor blood typing, such as mistaking $\mathrm{A}$ or $\mathrm{B}$ subgroup for $\mathrm{O}$, resulting in $\mathrm{ABO}$ mismatched transplantation. Noticeably, $77.48 \%$ of the candidates carried irregular $\mathrm{ABO}$ antibodies, which can occur naturally or as a result of a previous blood transfusion, pregnancy, and chronic diseases (28). These relevant clinical events were associated with aberrant $\mathrm{ABO}$ gene expression and the production of blood group antibodies (29). Considering the complete expression of the $\mathrm{ABO}$ blood group antigen in the kidney (30-32), the irritation of the irregular antibody pretransplantation would complicate blood group typing and, ultimately, donor selection.

In our study we evaluated ABO genotype and blood antibody intensity and found that the mismatch rate of donor selection by serotype was high for all blood types (88.37-96.61\%) except type O. Clinically, type $A B$ candidates have the easiest outlook to choose a donor with a relatively short waiting time (23). However, our data demonstrated that $\mathrm{AB}$ candidates had the highest probability (96.61\%) of ABO-mismatched kidney transplantation. More importantly, 17.51\% (31/177) of AB candidates analyzed in our study were strongly recommended to choose a type $\mathrm{O}$ graft for better long-term outcome. Therefore, the negligence of $\mathrm{ABO}$ genotyping will increase the risk of delayed graft function and rejection. ABOi living donor kidney transplantation was pioneered in Japan with excellent reported outcomes (33). The immunosuppressive regimen was adjusted and a splenectomy was completed according to serum ABO antibodies. The risk of early rejection and severe infection was higher in ABOi groups (34). Besides, it is a common phenomenon that blood transfusion for patients with renal anemia is lack of standardization in primary medical institution, which further increased the possibility of errors in serotyping later. We presented simulated mismatch rates here to estimate the huge risk in donor selection by serotyping only.

The A2 allele was characterized by a single base deletion (1061del C) compared with the A102 allele $(35,36)$, resulting in both a qualitative and quantitative difference between A1 and A2. The transferase activity of A1 is 5- to 10 -fold greater than that of A2 and is much higher than that of other weak A subgroups (37). Therefore, A1-to-A2 transplantation can induce antibodymediated rejection, whereas A2 and other weak A subgroups can be an alternative choice for type $\mathrm{O}$ candidates due to decreased A antigen expression on the renal endothelial cells $(38,39)$. In our previous report, a recipient experienced four AR episodes within 3 to 10 months post-transplantation, and graft function continued to decrease progressively after empirical administration of high dose methylprednisolone. The patient experienced graft loss 1 year after transplantation. Posttransplant $\mathrm{ABO}$ genotyping showed an A1O1-to-A2O1 mismatch, which was further confirmed by the 


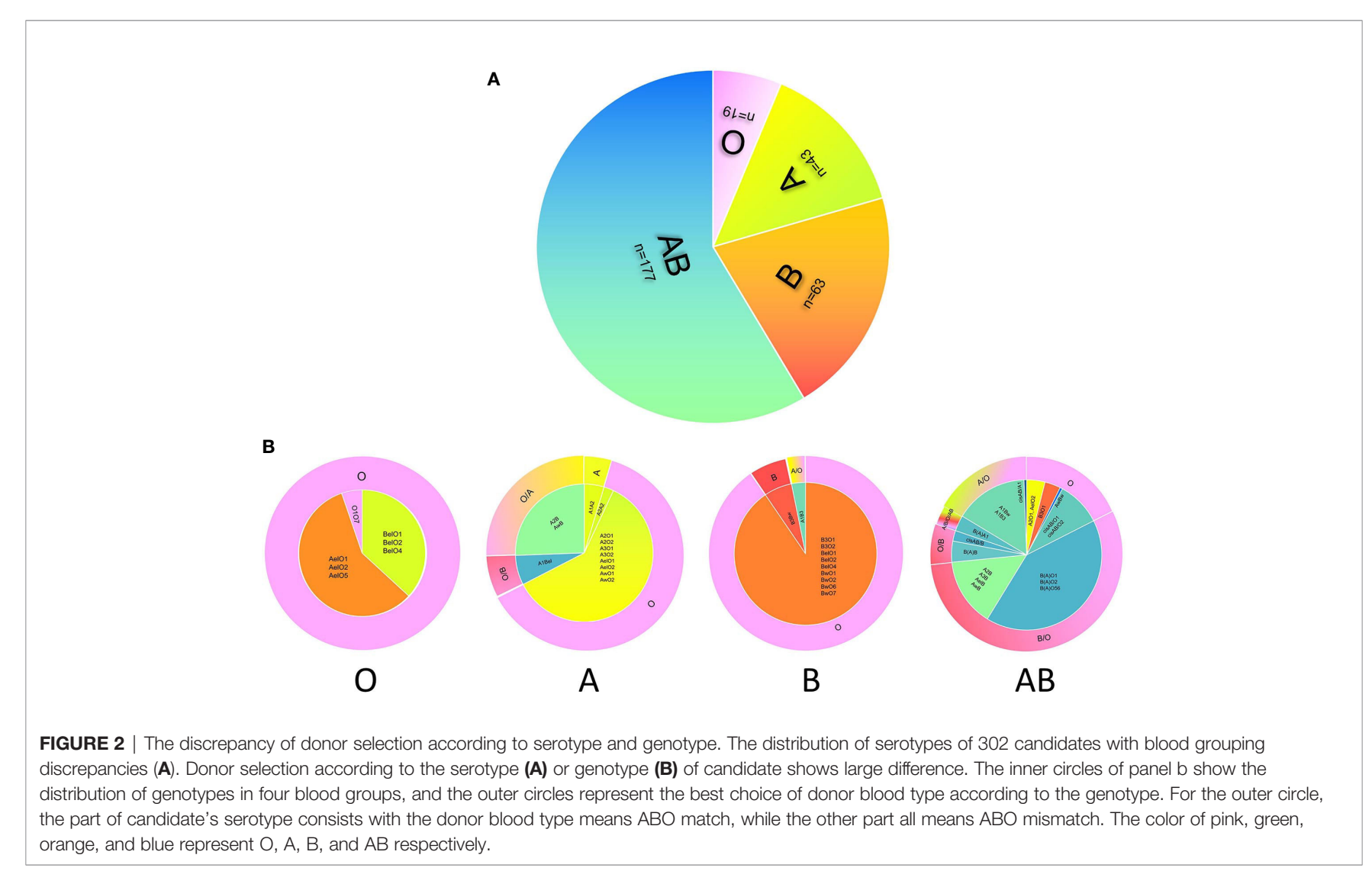

TABLE 4 | The distribution of weak A subgroup in different populations.

\begin{tabular}{|c|c|c|c|c|c|c|}
\hline Population & Total A (n) & Weak A (n) & Weak A \% & Lower & Upper & References \\
\hline American & 84 & 16 & $19.05 \%$ & & & Nelson PW et al. \\
\hline Chinese (Zhejiang) & 8,707 & 36 & $0.41 \%$ & $0.29 \%$ & $0.57 \%$ & Ying $Y$ et al. \\
\hline Chinese (Nanjing) & 7,839 & 24 & $0.31 \%$ & $0.20 \%$ & $0.46 \%$ & Chen $\mathrm{Y}$ et al. \\
\hline Chinese (Shandong) & 3,395 & 22 & $0.65 \%$ & $0.41 \%$ & $0.98 \%$ & Du Z et al. \\
\hline Chinese (Guangdong) & 6,664 & 16 & $0.24 \%$ & $0.14 \%$ & $0.39 \%$ & Xie $J$ et al. \\
\hline
\end{tabular}

TABLE 5 | The distribution of A subtypes in 356 candidates.

\begin{tabular}{|c|c|c|c|c|c|}
\hline \multirow{2}{*}{$\begin{array}{l}\text { Serotype } \\
A\end{array}$} & \multirow{2}{*}{$\begin{array}{l}\text { Phenotype } \\
\text { A1 }\end{array}$} & \multirow{2}{*}{$\begin{array}{l}\text { Genotype } \\
\text { A1A1 }\end{array}$} & \multirow{2}{*}{$\begin{array}{c}\text { Individuals } \\
51\end{array}$} & \multicolumn{2}{|c|}{ Relative frequency (\%) } \\
\hline & & & & 14.33 & 97.47 \\
\hline & & $\mathrm{A} 1 \mathrm{~A} 2$ & 2 & 0.56 & \\
\hline & & $\mathrm{A} 101$ & 181 & 50.84 & \\
\hline & & $\mathrm{A} 1 \mathrm{O} 2$ & 108 & 30.34 & \\
\hline & & $\mathrm{A} 1 \mathrm{O} 4$ & 5 & 1.40 & \\
\hline & Non A1 & $\mathrm{A} 2 \mathrm{O} 1$ & 3 & 0.84 & 2.53 \\
\hline & & $\mathrm{A} 2 \mathrm{O} 2$ & 4 & 1.12 & \\
\hline & & AwO2 & 2 & 0.56 & \\
\hline
\end{tabular}

antibody detection of anti-A1 in the serum with negative panel reactive antibody $(38,39)$.

Our results also showed that the actual weak A subgroup was larger than previously estimated by serotype screening. A donor graft in the weak ABO subgroup may not be precisely allocated if without genotyping. The United Network for Organ Sharing (UNOS) advocates A2-to-O/B transplantation to shorten the waiting time for type $\mathrm{O} / \mathrm{B}$ candidates (12). However, due to the rareness of A2 individuals in our country, it cannot be the common alternative for the $\mathrm{O}$ blood group. Therefore, we recommend precise $\mathrm{ABO}$ genotyping prior to kidney transplantation to guarantee genotypically $\mathrm{ABO}$-matched transplants as well as rational use of grafts in weak $\mathrm{ABO}$ subgroups.

\section{CONCLUSIONS}

The state of shrinking supply of corpus organs maintains. Due to the frequent occurrence of irregular $\mathrm{ABO}$ antibodies and the 
discrepancy between serotyping and genotyping, precise $\mathrm{ABO}$ genotyping protocols are urgently required for donor selection in kidney transplant candidates in order to reduce the risk of acute rejection and improve the rationality of organ allocation.

\section{DATA AVAILABILITY STATEMENT}

The original contributions presented in the study are included in the article/Supplementary Material. Further inquiries can be directed to the corresponding authors.

\section{ETHICS STATEMENT}

The studies involving human participants were reviewed and approved by Ethics committees of Nanfang Hospital, Southern Medical University. The patients/participants provided their written informed consent to participate in this study (NFEC2019-172).

\section{AUTHOR CONTRIBUTIONS}

YZ, YCW, LX, and YM designed the study. DL, NC, YHW, KQ, and SW carried out experiments. WD, HL, and SF analyzed the data. YCW made figures. YZ, JX, HN, and FX drafted and revised the paper. All authors contributed to the article and approved the submitted version.

\section{REFERENCES}

1. Yamamoto F, Clausen H, White T, Marken J, Hakomori S. Molecular genetic basis of the histo-blood group ABO system. Nature (1990) 345:229. doi: $10.1038 / 345229 \mathrm{a} 0$

2. Yamamoto F, McNeill PD, Hakomori S. Genomic organization of human histo-blood group ABO genes. Glycobiology (1995) 5:51. doi: 10.1093/glycob/ 5.1 .51

3. Anstee DJ. Red cell genotyping and the future of pretransfusion testing. Blood (2009) 114:248. doi: 10.1182/blood-2008-11-146860

4. Ogasawara K, Yabe R, Uchikawa M, Saitou N, Bannai M, Nakata K, et al. Molecular genetic analysis of variant phenotypes of the ABO blood group system. Blood (1996) 88:2732. doi: 10.1182/blood.V88.7.2732.bloodjournal 8872732

5. Huang H, Jin S, Liu X, Wang Z, Lu Q, Fan L, et al. Molecular genetic analysis of weak $\mathrm{ABO}$ subgroups in the Chinese population reveals ten novel $\mathrm{ABO}$ subgroup alleles. Blood Transfus (2019) 17:217 doi:10.2450/2018.0091-18

6. Hosoi E. Biological and clinical aspects of ABO blood group system. J Med Invest (2008) 55:174. doi: 10.2152/jmi.55.174

7. Anstee DJ. The relationship between blood groups and disease. Blood (2010) 115:4635. doi: 10.1182/blood-2010-01-261859

8. Kawase T, Abe M, Ishii T, Murakami T, Utumi K, Tojimbara T, et al. Shortterm results in $\mathrm{ABO}$-incompatible living related kidney transplantation. Transplant Proc (2002) 34:2773. doi: 10.1016/S0041-1345(02)03405-X

9. Goodwin W, MIMS MM, KAUFMAN JJ. Human renal transplantation. III. Technical problems encountered in six cases of kidney homotransplantation. J Urol (1963) 89:349. doi: 10.1016/S0022-5347(17)64556-7

10. Gloor JM, Lager DJ, Moore SB, Pineda AA, Fidler ME, Larson TS, et al. ABOincompatible kidney transplantation using both A2 and non-A2 living donors. Transplantation (2003) 75:971. doi: 10.1097/01.TP.0000058226.39732.32

11. Westhoff CM. Blood group genotyping. Blood (2019) 133:1814. doi: 10.1182/ blood-2018-11-833954

\section{FUNDING}

This study was funded by the Science and Technology Planning Project of Guangzhou (Grant No. 201803010109), Natural Science Foundation of Guangdong Province (Grant No. 2020A1515010674), the President Funding of Nanfang Hospital (Grant No. 2018B009, 2018C003) and College Students' Innovative Entrepreneurial Training Plan Program (Grant No. 201812121148, X202012121239, 202012121046).

\section{ACKNOWLEDGMENTS}

The work has been previously presented in American Transplant Congress 2020 (ATC2020) as Abstract D-020: Zhou Y, Deng W, Wang Y, Cui N, Wu Y, Xu J, Fu S, Xiao L, Liu H, Xiong F, Miao Y. The Potential Significance of ABO Genotyping for Donor Selection in Kidney Transplantation [abstract]. Am J Transplant. 2020; 20 (suppl 3).

\section{SUPPLEMENTARY MATERIAL}

The Supplementary Material for this article can be found online at: https://www.frontiersin.org/articles/10.3389/fimmu.2020. 608716/full\#supplementary-material.

12. Bryan CF, Nelson PW, Shield CR, Ross G, Warady B, Murillo D, et al. Transplantation of A2 and A2B kidneys from deceased donors into B waiting list candidates increases their transplantation rate. Clin Transpl (2004) 127-33.

13. Kluger MD, Guarrera JV, Olsen SK, Brown RJ, Emond JC, Cherqui D. Safety of blood group A2-to-O liver transplantation: an analysis of the United Network of Organ Sharing database. Transplantation (2012) 94:526. doi: 10.1097/TP.0b013e31825c591e

14. Wang M, Lv J, Chen P, Yu G, Shi S, Liu L, et al. Associations of ABO blood type and galactose-deficient immunoglobulin A1 with adverse outcomes in patients with IgA nephropathy. Nephrol Dial Transplant (2019), gfz171e. doi: 10.1093/ndt/gfz171

15. Yu L, Lin TC, Deng WF, Wang YB, Ye J, Miao Y, et al. Association of ABO genotype with acute rejection in renal transplantation. Chin J Urol (2010) 31:814. doi: 10.3760/cma.j.issn.1000-6702.2010.12.008

16. Ying Y, Hong X, Xu X, Liu Y, Lan X, Ma K, et al. Serological characteristic and molecular basis of A2 subgroup in the Chinese population. Transfus Apher Sci (2013) 48:67. doi: 10.1016/j.transci.2012.08.002

17. Chen Y, Ma L, Zhu S, Shi L, Liu Y, Chen B. Analysis and research on molecular mechanisms of A subgroups in Nanjing Han population. J Clin Hematol (China) (2016) 29:773. doi: 10.13201/j.issn.1004-2806-b.2016.10.001

18. Du Z, Mou X, Wei L, Zhao X, Mu B. Comparative analysis of A2 subtype serological and genotyping results. China Modern Med (2012) 19:175. doi: 10.3969/j.issn.1674-4721.2012.25.092

19. Xie J, Liu S, Lan W, Mo J, Ma W, Yan K, et al. Genotypic study of ABO subtypes in Panyu area. Chin J Blood Transfusion (2016) 29:381. doi: 10.13303/j.cjbt.issn.1004-549x.2016.04.014

20. Nelson PW, Helling TS, Pierce GE, Ross G, Shield CF, Beck ML, et al. Successful transplantation of blood group A2 kidneys into non-A recipients. Transplantation (1988) 45:316. doi: 10.1097/00007890-198802000-00013

21. Daniels G. Human blood groups. 2nd ed. Oxford: Blackwell (2002).

22. Gassner C, Schmarda A, Nussbaumer W, Schonitzer D. ABO glycosyltransferase genotyping by polymerase chain reaction using sequence-specific primers. Blood (1996) 88:1852. doi: 10.1182/blood.V88.5.1852.bloodjournal8851852 
23. Flechner SM, Thomas AG, Ronin M, Veale JL, Leeser DB, Kapur S, et al. The first 9 years of kidney paired donation through the National Kidney Registry: Characteristics of donors and recipients compared with National Live Donor Transplant Registries. Am J Transplant (2018) 18:2730. doi: 10.1111/ajt.14744

24. Weng FL, Grogan T, Patel AM, Mulgaonkar S, Morgievich MM. Characteristics of compatible pair participants in kidney paired donation at a single center. Clin Transplant (2017) 31:10.1111. doi: 10.1111/ctr.12978

25. Eiz-Vesper B, Seltsam A, Blasczyk R. ABO glycosyltransferases as potential source of minor histocompatibility antigens in allogeneic peripheral blood progenitor cell transplantation. Transfusion (2005) 45:960. doi: 10.1111/ j.1537-2995.2005.04370.x

26. Ushigome H, Okamoto M, Koshino K, Nobori S, Okajima H, Masuzawa N, et al. Findings of graft biopsy specimens within 90 days after ABO blood group incompatible living donor kidney transplantation compared with $\mathrm{ABO}$ identical and non-identical transplantation. Clin Transplant (2010) 24 Suppl 22:16. doi: 10.1111/j.1399-0012.2010.01278.x

27. Dashkova NG, Ragimov AA, Asoskova TK. Significance of the isoantigen A2 and immune anti-A1 antibodies in transfusiology. Anesteziol Reanimatol (2009) 6:62.

28. Olsson ML, Irshaid NM, Hosseini-Maaf B, Hellberg A, Moulds MK, Sareneva H, et al. Genomic analysis of clinical samples with serologic $\mathrm{ABO}$ blood grouping discrepancies: identification of 15 novel A and B subgroup alleles. Blood (2001) 98:1585. doi: 10.1182/blood.V98.5.1585

29. Bianco T, Farmer BJ, Sage RE, Dobrovic A. Loss of red cell A, B, and H antigens is frequent in myeloid malignancies. Blood (2001) 97:3633. doi: 10.1182/blood.V97.11.3633

30. Bariety J, Oriol R, Hinglais N, Zanetti M, Bretton R, Dalix AM, et al. Distribution of blood group antigen $\mathrm{A}$ in normal and pathologic human kidneys. Kidney Int (1980) 17:820. doi: 10.1038/ki.1980.94

31. Trickett LP, Evans PR, MacIver AG, Smith JL, Slapak M. Variable localization of blood group antigen in group A kidneys. Br J Exp Pathol (1983) 64:137.

32. Cordon-Cardo C, Reuter VE, Finstad CL, Sheinfeld J, Lloyd KO, Fair WR, et al. Blood group-related antigens in human kidney: modulation of Lewis determinants in renal cell carcinoma. Cancer Res (1989) 49:212.

33. Holscher CM, Jackson KR, Segev DL. Transplanting the Untransplantable. Am J Kidney Dis (2020) 75:114. doi: 10.1053/j.ajkd.2019.04.025
34. de Weerd AE, Betjes M. ABO-Incompatible Kidney Transplant Outcomes: A Meta-Analysis. Clin J Am Soc Nephrol (2018) 13:1234. doi: 10.2215/ CJN.00540118

35. Hakomori S. Antigen structure and genetic basis of histo-blood groups A, B and O: their changes associated with human cancer. Biochim Biophys Acta (1999) 1473:247. doi: 10.1016/S0304-4165(99) 00183-X

36. Yamamoto F, McNeill PD, Hakomori S. Human histo-blood group A2 transferase coded by $\mathrm{A} 2$ allele, one of the A subtypes, is characterized by a single base deletion in the coding sequence, which results in an additional domain at the carboxyl terminal. Biochem Biophys Res Commun (1992) 187:366. doi: 10.1016/S0006-291X(05)81502-5

37. Chang CS, Lin KT, Chang JG, Lin CW, Hsieh LL, Yeh CJ, et al. Molecular basis of the A2B in Taiwan. Int J Hematol (2008) 88:127. doi: 10.1007/s12185008-0136-X

38. Breimer ME, Molne J, Norden G, Rydberg L, Thiel G, Svalander CT, et al. and $\mathrm{B}$ antigen expression in human kidneys correlated to A1/A2/B, Lewis, and secretor status. Transplantation (2006) 82:479. doi: 10.1097/ 01.tp.0000231697.15817.51

39. Breimer ME, Samuelsson BE. The specific distribution of glycolipid-based blood group A antigens in human kidney related to A1/A2, Lewis, and secretor status of single individuals. A possible molecular explanation for the successful transplantation of A2 kidneys into O recipients. Transplantation (1986) 42:88. doi: 10.1097/00007890-198607000-00021

Conflict of Interest: The authors declare that the research was conducted in the absence of any commercial or financial relationships that could be constructed as a potential conflict of interest.

Copyright (C) 2020 Zhou, Wang, Ni, Deng, Liu, Xu, Cui, Wu, Fu, Xiao, Liu, Qi, Wang, Xiong and Miao. This is an open-access article distributed under the terms of the Creative Commons Attribution License (CC BY). The use, distribution or reproduction in other forums is permitted, provided the original author(s) and the copyright owner(s) are credited and that the original publication in this journal is cited, in accordance with accepted academic practice. No use, distribution or reproduction is permitted which does not comply with these terms. 